\title{
Sources of Indoor Air Pollution and Respiratory Health in Preschool Children
}

\author{
Virginia Fuentes-Leonarte, ${ }^{1,2}$ Ferran Ballester, ${ }^{1,2}$ and José Maria Tenías ${ }^{2,3}$ \\ ${ }^{1}$ Department of Health and Environment, Centre for Public Health Research (CSISP), 46020 Valencia, Spain \\ ${ }^{2}$ CIBER Epidemiology and Public Health (CIBERESP), 8003 Barcelona, Spain \\ ${ }^{3}$ Research Support Unit, Hospital La Mancha Centro, 13600 Alcázar de San Juan, Spain \\ Correspondence should be addressed to Ferran Ballester, ballester_fer@gva.es
}

Received 25 August 2009; Accepted 2 November 2009

Recommended by David O. Carpenter

\begin{abstract}
We carried out bibliographic searches in PubMed and Embase.com for the period from 1996 to 2008 with the aim of reviewing the scientific literature on the relationship between various sources of indoor air pollution and the respiratory health of children under the age of five. Those studies that included adjusted correlation measurements for the most important confounding variables and which had an adequate population size were considered to be more relevant. The results concerning the relationship between gas energy sources and children's respiratory health were heterogeneous. Indoor air pollution from biomass combustion in the poorest countries was found to be an important risk factor for lower respiratory tract infections. Solvents involved in redecorating, DYI work, painting, and so forth, were found to be related to an increased risk for general respiratory problems. The distribution of papers depending on the pollution source showed a clear relationship with life-style and the level of development.
\end{abstract}

Copyright ( $) 2009$ Virginia Fuentes-Leonarte et al. This is an open access article distributed under the Creative Commons Attribution License, which permits unrestricted use, distribution, and reproduction in any medium, provided the original work is properly cited.

\section{Introduction}

In our society, most people spend the majority of their time indoors, at home, work, or school, in public buildings, and so forth. For this reason, the quality of indoor air affects the quality of life and the well-being of the population in general, with the exposure to diverse indoor pollutants presenting a higher risk for developing various diseases such as those affecting the respiratory system [1].

Young children constitute a special risk group due to the fact that their respiratory system is not yet completely developed until the age of six. Thus, for example, while the number of alveoli at birth is approximately 24 million, by the age of four, this number increases to 250 million [2]. Furthermore, children breathe more air in proportion to their weight than adults and, in the case of very young children, they spend proportionally more time indoors. For all these reasons, the first years of life constitute a critical period for an individual's exposure to air pollution.

The principal sources of indoor air pollution are linked to the methods used to heat the home as well as to the domestic activities related to the preparation of food (cooking). Other habitual pollution sources include the use of tobacco and of chemical products used for cleaning, building, and decorating [3].

In developing countries, the population depends on wood, coal, or biomass fuels to satisfy their basic energy needs [4]. Cooking and/or heating with these energy sources, in many cases over open fires and with no chimney or exhaust system, leads to significant concentrations of indoor air pollution, including both gases and particles in suspension. In poorly ventilated houses in which this type of fuel is used, indoor pollution levels can reach concentrations up to 100 times greater than the currently established limits for outdoor air pollution. This type of exposure is particularly pronounced in women and children, who spend most of their time indoors and who dedicate more time to domestic chores.

According to the WHO [5], in the poorest countries up to $5 \%$ of the total amount of disease can be attributed to the use of solid fuels as energy sources. This percentage is in large part due to the impact of indoor air pollution on 
TABLE 1: Descriptors used in the bibliographic searches.

\begin{tabular}{llc}
\hline & PubMed & EMBASE (EMTREE) \\
\hline \multirow{2}{*}{ Respiratory diseases } & Respiratory Tract & Respiratory tract disease \\
& Diseases & \\
Indoor air pollution & Air Pollution, & Indoor air pollution \\
& Indoor & \\
Children & Infant, newborn & Newborn \\
& Infant & Infant \\
& Child, preschool & Preschool \\
\hline
\end{tabular}

deaths caused by acute respiratory infections (ARIs), which cause $19 \%$ of deaths in children under the age of five [6].

In the developed world, domestic combustion sources tend to be cleaner, using fuel sources such as gas and electricity. In these countries, problems of indoor air pollution tend to be related to other compounds such as nitrogen dioxide, derivatives from tobacco smoke, volatile organic compounds (VOCs), and other chemical compounds [3]. In addition, in order to save energy and maintain a constant indoor temperature, the windows of the buildings are rarely opened; indeed, there is a trend to design buildings with ever greater amounts of insulation. For these reasons, the renovation of the indoor air diminishes and, because the channelling of pollution generated by indoor sources to the exterior of the building is increasingly avoided, the concentration of indoor air pollution increases correspondingly.

In a previous paper [7] we reviewed articles published on indoor air pollution levels and the respiratory health of children. However, from the point of view of prevention, it may be more useful to have at our disposal evidence related to the sources of the exposure, such as the types of domestic appliances that emit gases, the burning of fuel in the home, or the use of chemical products that emit gases in building interiors. The identification of those sources most related to the effects on health in young children would allow for the establishment of strategies to reduce exposure, and, as a consequence, health problems in this subset of the population. Our objective is thus to review the scientific literature on the relationship between various sources of indoor air pollution and the respiratory health of children under the age of five.

\section{Materials and Methods}

The bibliographic searches were carried out with PubMed (National Library of Medicine and National Institute of Health) and Embase.com (Elsevier). The period chosen was from the years 1996 to 2008, both inclusive. No restrictive criteria were set concerning the language of publication.

We chose to undertake the most exhaustive search possible. As such, the broadest descriptors were used to identify those articles dedicated to respiratory illness and indoor air pollution (Table 1). The limit for the age of the subjects was set at under five years of age.

We looked for studies in which correlation measures were established between one or more indoor pollution sources and at least one indicator of respiratory health in children under five. Those studies in which the only source of pollution examined was the passive exposure to tobacco smoke were not included in the present review because the sheer volume of publications on this topic merits separate consideration. A major selection criterion was that the source(s) of indoor air pollution was clearly identified in the published work. So, studies in which the pollutants are measured as levels but without a source of pollution identified were excluded. In case of doubt, the entire text was read.

We then proceeded to extract and classify the information using a table agreed upon through consensus in which the following items were used: country (distinguishing between developed and developing countries), type of study, author and year of publication, and population data, which included age of the subjects and number of cases. With regard to the health indicators, the items were as follows: definition of the incidence and information source (questionnaire, interview, clinical visit, etc.). With regard to exposure, we classified the pollution source. We also collected the adjusted correlation measurements and the interval of confidence $95 \%$ values as well as the adjustment variables that were examined. The possibility of carrying out a metaanalysis was considered taking into account the criteria that more than two studies analyzing the impact of the same type of pollution source on the same health indicator in comparable populations were found.

The results of those studies which provided adjusted correlation values for the most important confounding variables were considered to be the most relevant. These variables included sociodemographic data, parents' background, personal background, and especially the presence of other pollutants, both indoors and out. In addition, those studies with an adequate sample size which used a cohort or a casecontrol design within a cohort were considered to be of greater relevance, as were those in which the case definition was clear and rigorous. Each study was critically appraised identifying possible threats to its internal validity.

\section{Results and Discussion}

3.1. Results. A total of 332 documents were obtained from a first reading of the abstracts: 143 were found exclusively on PubMed and 123 on EMBASE, with 66 studies appearing in both data bases (19.9\%). Finally, 25 publications were considered to be relevant in accordance with the aforementioned criteria.

\subsubsection{Studies Analyzing the Relationship between Gas-Powered Indoor Pollution Sources and Respiratory Problems (See Table 2). Nine studies which met the selection criteria were identified; five were cohort studies, two had a transversal design, and two were case-control studies, one of which took place within a cohort. \\ Five of the studies were carried out in the United States, two in Europe (Sweden, Spain, and the United Kingdom), and two in Africa (Zimbabwe and South Africa).}




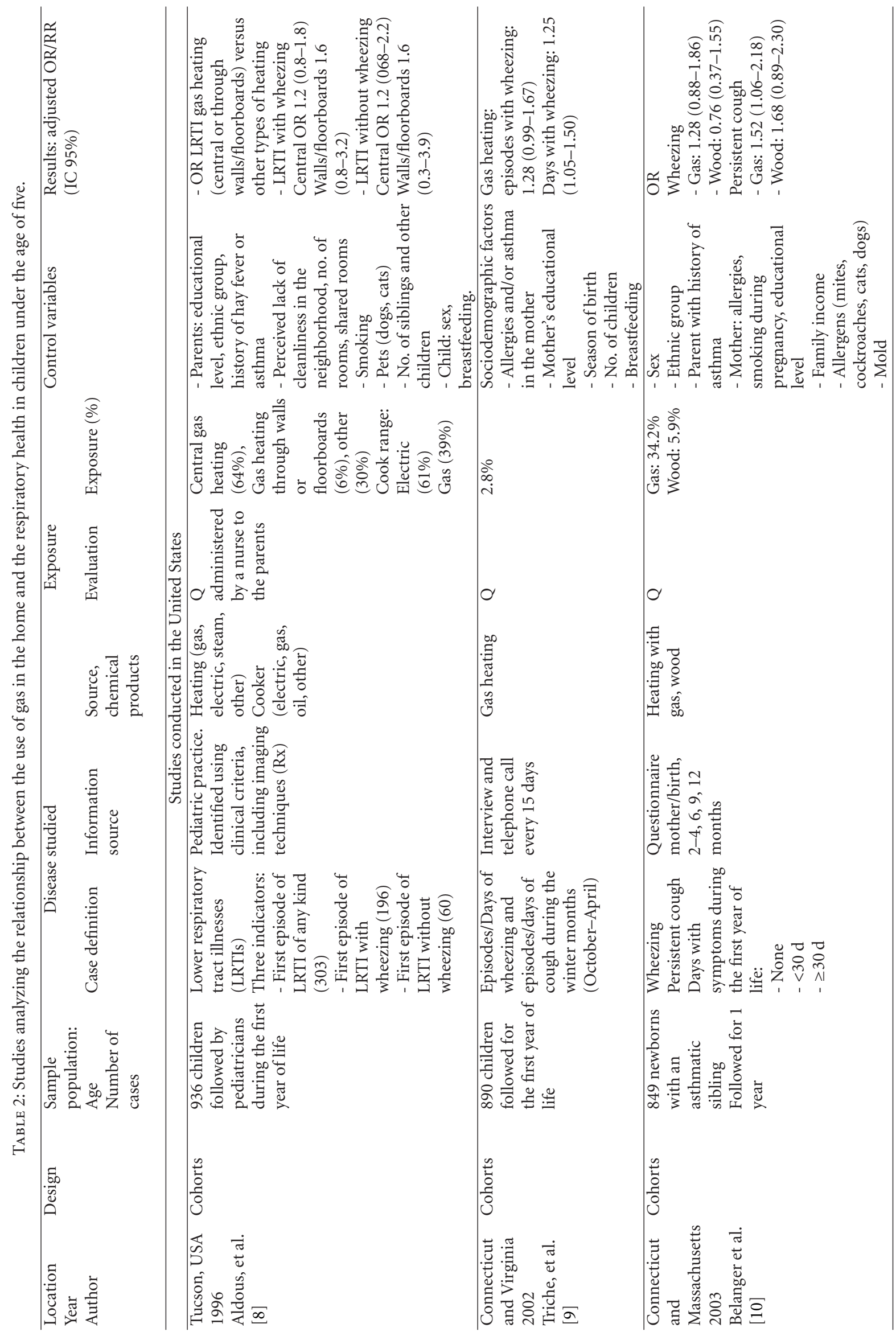




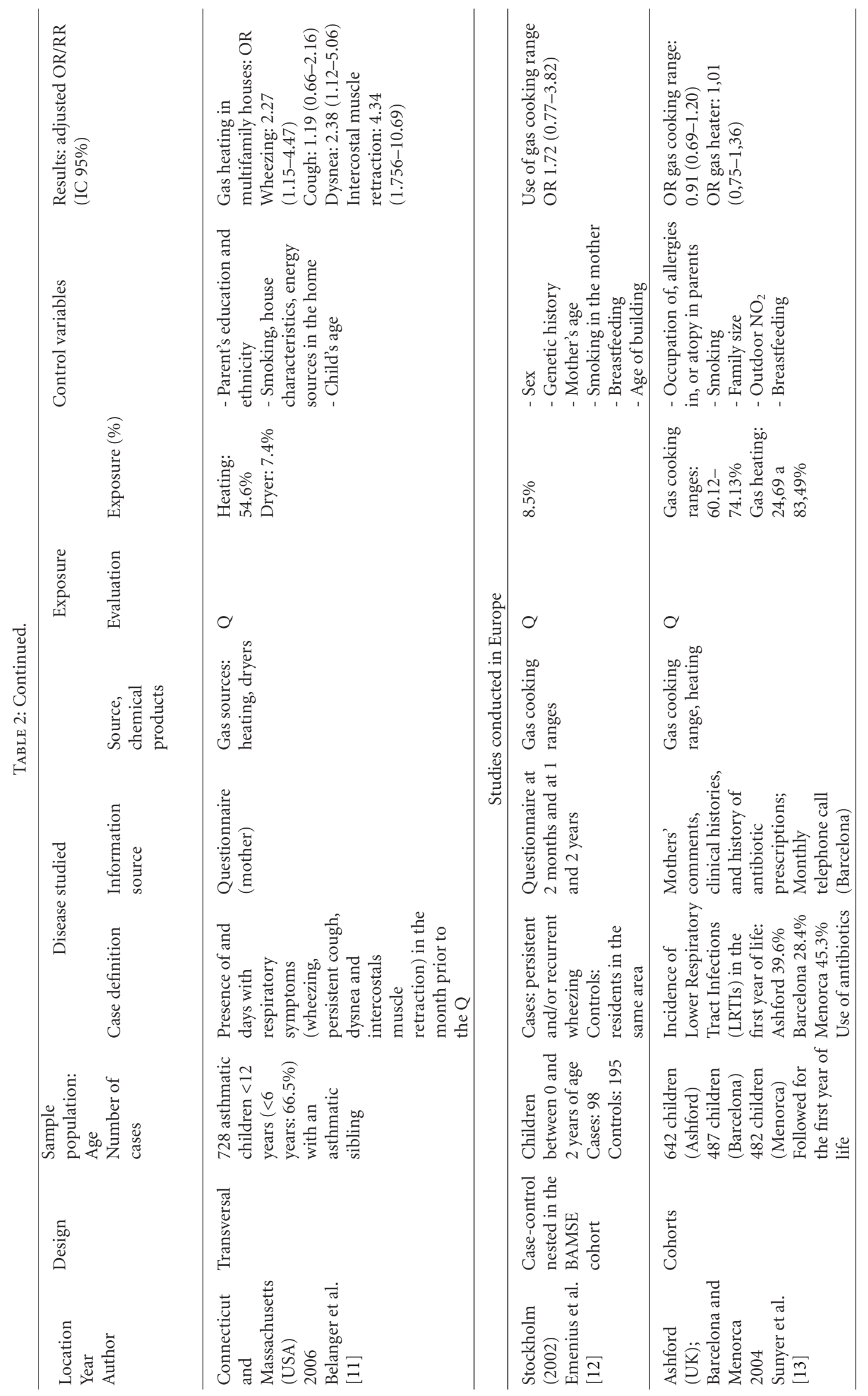




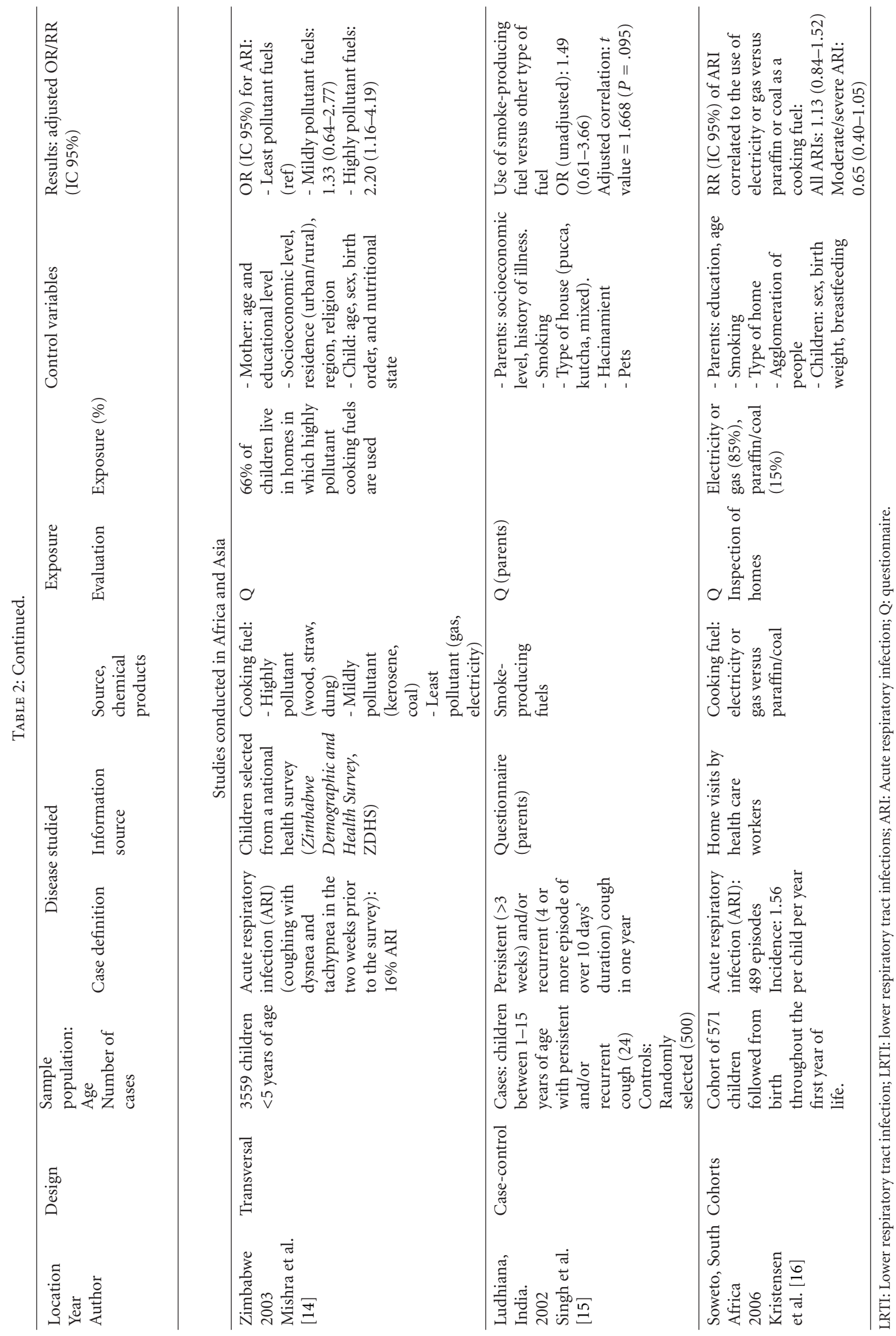


Studies Carried Out in the U.S. Using a cohort of 936 children living in Tucson, Arizona, Aldous et al. [8] studied the development of lower respiratory tract illnesses (LRTIs) during the first year of life. The authors took various domestic exposure factors into consideration, including the energy sources used for heating, refrigeration, and cooking. They observed an increase in LRTIs in those children who lived in houses with cooling systems based on the evaporation of a cold liquid into the indoor air: OR 1.8 (IC 95\% 1.1-3.0) for LRTIs involving difficulties breathing (wheezing), and OR 1.5 (IC 95\% 0.7-4.0) for LRTIs without breathing difficulties. The authors attributed this increase in risk to a greater exposure to molds, mites, and pollen coming from the cooling system. Gas heating was also linked to an increase in risk, especially for LRTIs with wheezing. In addition, the authors noted a positive and significant tendency related to the perceived lack of cleanliness in the neighborhood.

In Connecticut and Virginia, Triche et al. [9] followed a cohort of children up to their first birthdays, noting episodes of coughing and wheezing. The authors linked the incidence of both symptoms to the type of fuel used for heating, finding a positive and significant relationship between the symptoms observed and gas heating, for example (RR 1.25; IC 95\% $1.05-1.50)$. The estimates were adjusted for various types of confounding variables; moreover, the homes of smokers were excluded from the study.

In their study conducted in Connecticut and Massachusetts, Belanger et al. [10] recruited a cohort of children with a high risk for developing asthma (all had one asthmatic sibling) and followed them during their first year of life. Through questionnaires, the mothers recorded the appearance of respiratory symptoms (persistent wheezing and cough). The authors analyzed the indoor exposure by typifying the use of gas or wood as energy sources together with monitoring levels of $\mathrm{NO}_{2}$ and different allergens. The use of gas heaters was correlated in a statistically significant way to the incidence of persistent cough in children of mothers with no personal history of asthma. A similar correlation was found when the energy source was substituted for $\mathrm{NO}_{2}$ concentrations, with a $21 \%$ increase in the frequency of persistent cough for each $10 \mathrm{ppb}$ increase in $\mathrm{NO}_{2}$ levels (IC 95\% 5-40\%).

These same authors later conducted a transversal study with a different cohort [11] to examine the relationship between the use of gas energy sources (versus other types of fuel) and respiratory problems. They observed a significant correlation between wheezing and intercostals muscle retractions in children who lived in multifamily housing. When they replaced the gas source with $\mathrm{NO}_{2}$ levels in the regression models, they found a significant relationship with both symptoms. They concluded that this compound may explain in part the relationship between gas energy sources and these symptoms.

Studies Conducted in Europe. In a cohort of children born in Stockholm, Emenius et al. [12] carried out a nested casecontrol study, conducted when the children were between 1 and 2 years of age, in which the relationship between exposure to various types of domestic pollution and the incidence of persistent wheezing (3 or more episodes unrelated to the common cold from the age of 3 months together with symptoms of bronchial hyperreactivity such as coughing while sleeping, playing, or laughing) was evaluated. In the multivariate analysis, the authors observed a higher risk in children who lived in homes with gas cooking ranges (OR 1.72; IC 95\% 0.77-3.87), although few homes (8.5\%) actually cooked with gas. Increases in indoor $\mathrm{NO}_{2}$ levels were not associated with the aforementioned symptoms in a significant fashion (OR 1.06; IC 95\% 0.74-1.52), although there was a significant relationship between the symptoms and outdoor $\mathrm{NO}_{2}$ levels (RR 1.73; IC 95\% 1.05-2.82).

In three cohorts of children born in Spain (Barcelona and Menorca) and the United Kingdom (Ashford), Sunyer et al. [13] studied the relationship between indoor $\mathrm{NO}_{2}$ levels and the incidence of lower respiratory tract infections (LRTIs) in the first year of life. The results showed a lack of significant correlations between $\mathrm{NO}_{2}$ and LRTIs. Moreover, neither the use of gas cooking ranges or gas heating was associated with significant variations in the occurrence of LRTIs. In a previous study, [25] the authors had observed a close relationship between $\mathrm{NO}_{2}$ levels and the use of gas energy sources.

Studies Conducted in Africa and Asia. Kristensen and Olsen [16] followed a cohort of 571 children born in Soweto (South Africa) during the first year of life, noting the appearance of episodes of acute respiratory infections (ARIs). They did not find a significant association between the incidences of such episodes with the use of different cooking fuels.

In a sample representative of 3559 children under the age of five taken from a national health survey in Zimbabwe, Mishra [14] identified those cases with symptoms compatible with an ARI in the two weeks prior to the survey. They collected information about the type of cooking fuel used, classifying different types of fuels as follows: highly pollutant (wood, straw, dung), mildly pollutant (kerosene and coal), and least pollutant (gas and electricity). After adjusting for different variables, they found that the use of highly pollutant cooking fuels doubled the risk for respiratory infections. Other factors associated with this problem were the age of the child, with the most crucial period being between 6 and 11 months, and the area of residence.

In a case-control study, Singh et al. [15] analyzed various factors associated with persistent and/or recurrent cough in children between the ages of 1 and 15 living in the area of Ludhiana, in Northern India. Among other factors, the authors analyzed the relationship between this health problem and the use of smoke-producing fuels: kerosene, wood, cow dung, and so forth. They found a nonsignificant increase in the incidence of the symptoms and the use of these energy sources (unadjusted OR 1.49; IC 95\% 0.613.66).

3.1.2. Studies Analyzing the Relationship between Indoor Pollution from the Use of Solid Fuels, Biomass Fuels, Oil, and Kerosene with Respiratory Symptoms (Table 3). We found 


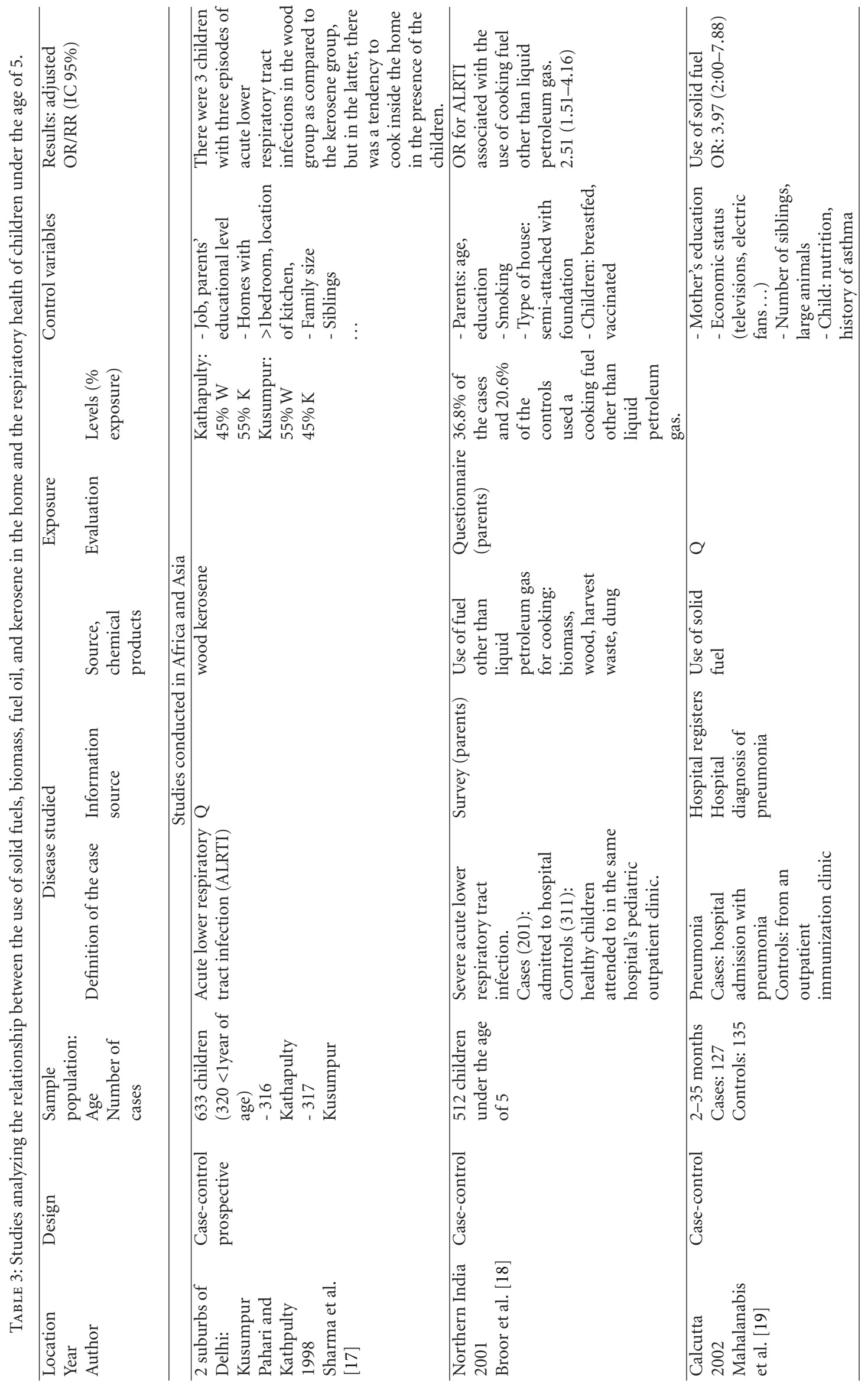




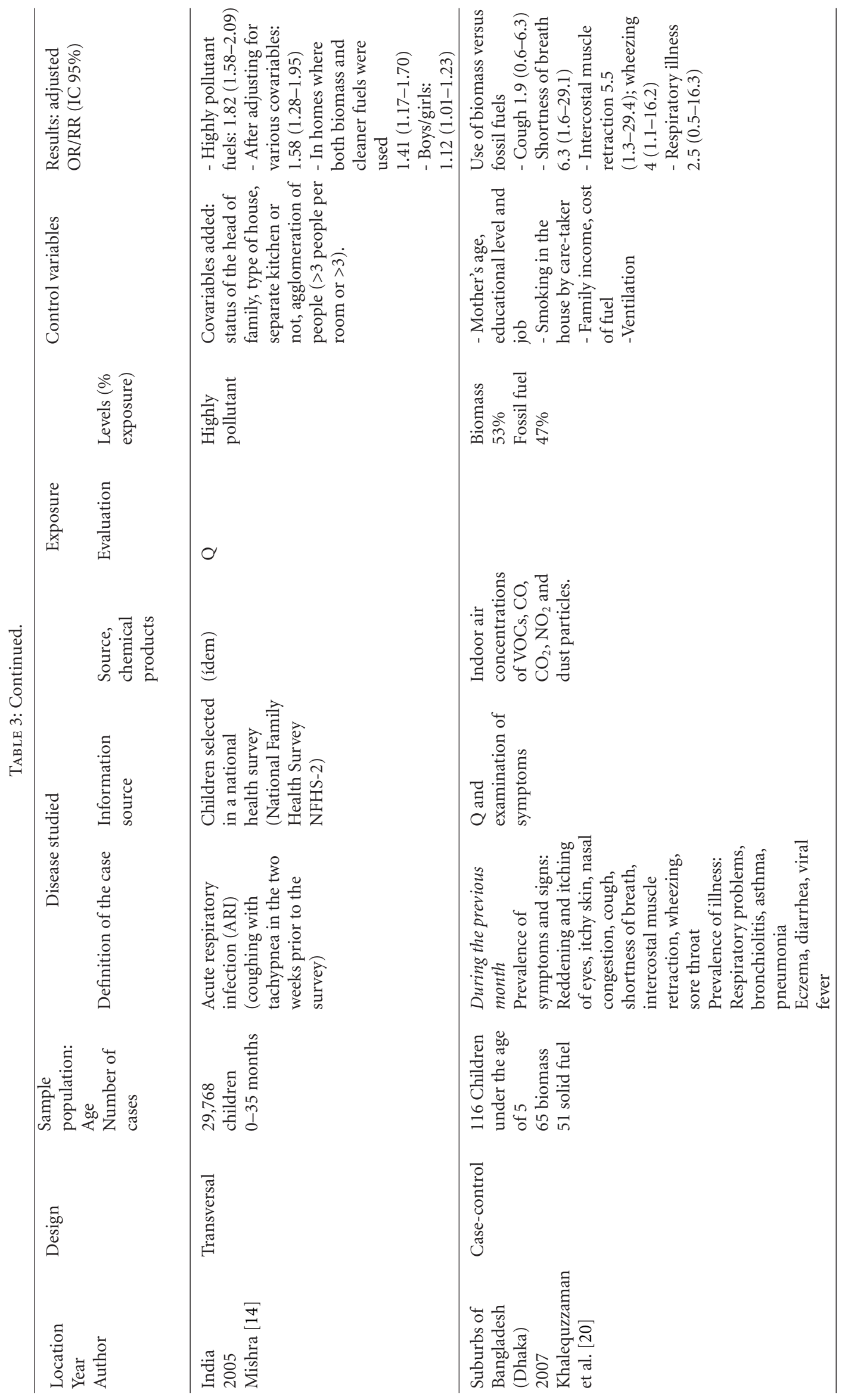




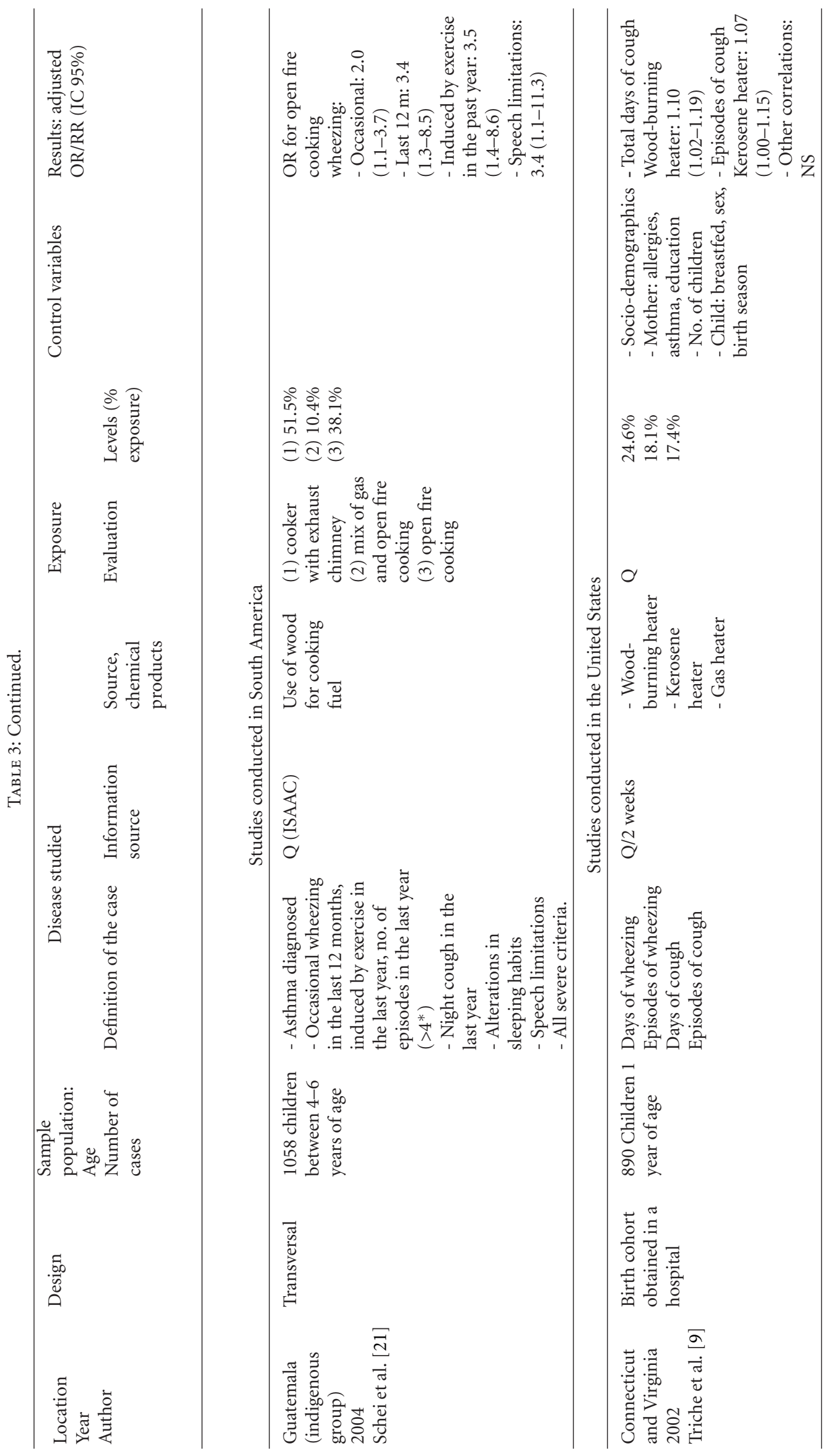




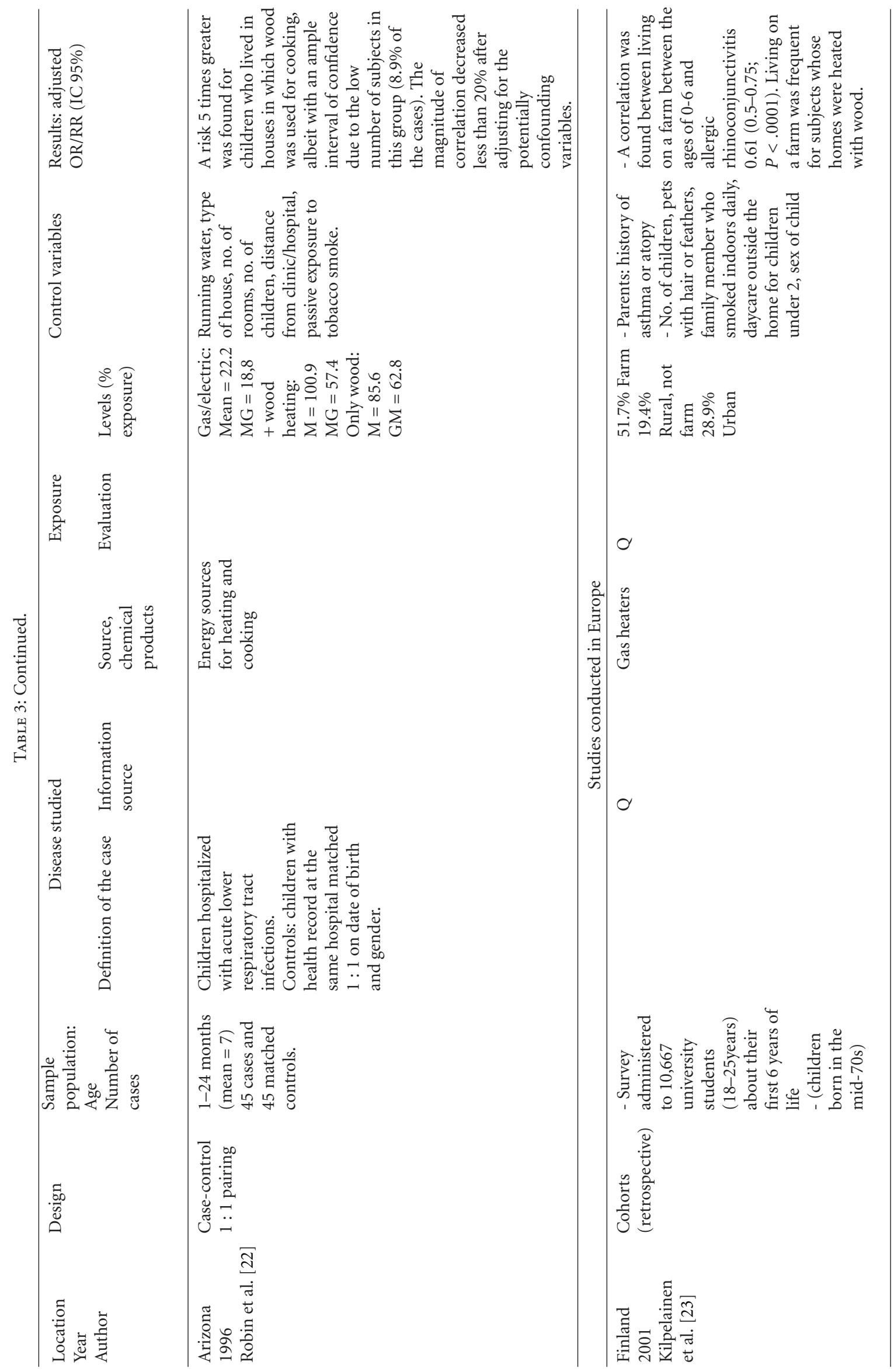




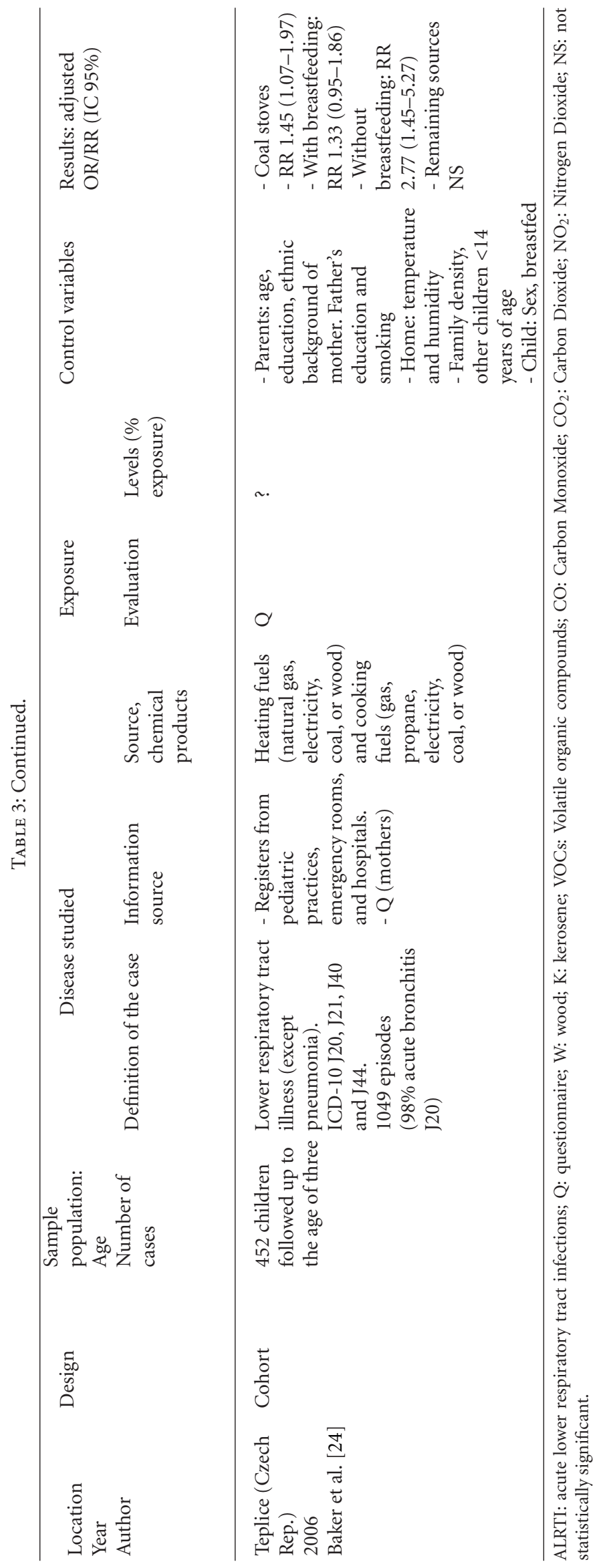


twelve studies dealing with this issue. The majority of them (seven) were carried out in communities in the developing world in which the population uses highly pollutant materials (biomass and coal) and inefficient instruments to meet their daily energy needs. Six of the studies had a casecontrol design, four used cohorts, and one was a transversal study.

Studies Conducted in Africa and Asia. In an exploratory study, Sharma et al. [17] examined two suburbs of Delhi. The authors compared the incidence of LRTIs in children under the age of four divided into two groups: those that lived in homes in which kerosene was used to cook and those in which wood was used as the main cooking fuel. No significant differences were observed, probably because the kerosene group showed a greater tendency to cook indoors in the presence of the children [17].

In a case-control study carried out in India by Broor et al. [18] with children under 5 to examine the relationship between the use of fuels other than liquid petroleum gas (LPG) and LRTIs, $36.8 \%$ of the cases and $20.6 \%$ of the controls used a fuel other than LPG. The authors observed a significant correlation between the incidence of LRTIs and the use of non-LPG cooking fuels: OR $=2.51$; IC 95\% $1.51-$ 4.16 [18]. Another case-control study conducted in Calcutta by Mahalanabis et al. (2002) in children between the ages of 2 and 35 months showed a clear correlation between the use of solid fuels and hospital admissions for pneumonia (OR: 3.97; IC 95\% 2.00-7.88) [19].

As commented above in the section on studies related to energy sources, Mishra (2003) [14] carried out a study in Zimbabwe using the Fourth Zimbabwe Demographic and Health Survey (ZDHS) to examine the relationship between acute respiratory infections, defined as the presence of cough and tachypnea in the two weeks prior to the survey in children under the age of five. The authors found that $66 \%$ of the children lived in homes in which highly pollutant fuels (wood, dung, straw) were used and that there was a significant correlation between the use of these fuels and the incidence of ARIs (OR: 2.20; IC 95\% 1.16-4.19) with respect to those who lived in homes in which cleaner fuels were used [19]. In a similar study carried out in India (2005) with children between 0 and 35 months of age, upon controlling for potentially confounding variables such as passive exposure to tobacco smoke (PETS), the authors found a positive, albeit slightly lower, correlation (OR: 1.41; IC 95\% 1.171.70) [26].

In the suburbs of Bangladesh (Dacca), Khalequzzaman et al. (2007) conducted a case-control study with children under 5. They evaluated the presence of respiratory symptoms and signs as well as respiratory disease (bronchiolitis, asthma, pneumonia) depending on the use of solid biomass fuels. In homes in which biomass was used as fuel, clear associations were found with shortness of breath (OR: 6.30; IC 95\% 1.60-29.1), intercostals muscle retraction (OR: 5.50; IC 95\%1.30-29.40), and wheezing (OR: 4 IC 95\% 1.1016.20) [20].
Studies Conducted in South America. In their study on a group of 20 children under the age of 2 along with 36 mothers, all residents of the state of Chiapas (Mexico), Riojas-Rodríguez et al. (2001) observed a protective, albeit nonsignificant, effect $(\mathrm{RR}=0.28$; IC 95\% 0.07-1.18) related to the use of closed "Ceta"-type ovens as opposed to the use of open fires for heating and cooking. This is due to the fact that the emission of particles in suspension-principally PM10 particles-is higher in the latter. This study was not included in the summary table as its principal objective was to study the correlation between respiratory symptoms and the levels of PM10 particles in suspension and the number of cases was very low [33].

In a transversal study carried out by Schei et al. (2004) in Guatemala with 1058 children between the ages of 4 and 6 , the authors used the ISAAC questionnaire to examine the presence of asthma symptoms (wheezing, night cough) in relationship to the cooking methods used in the home. In $51.5 \%$ of the homes, an oven with an exhaust chimney was used while gas and open fires were used in only in $10.4 \%$ of the homes. In 38.1\%, however, open fires were used. The authors observed a statistically significant relationship between the incidence of wheezing and the use of open fires for cooking [21].

Studies Conducted in the United States. In 1996, Robin et al. conducted a case-control study pairing hospital admissions for LRTIs in Navajo children between 1 and 24 months of age and the use of wood-burning stoves. They found an excess risk more than five times greater in those children who lived in houses in which wood was used as a cooking fuel, although with an ample interval of confidence given the low number of subjects in this group ( $8.9 \%$ of the cases). The magnitude of correlation diminished less than $20 \%$ after adjusting for potentially confounding variables [22].

In the cohort study conducted in Connecticut by Triche et al. (2002) [9], mentioned above in the section on gas energy sources, the incidence of wheezing and cough was evaluated during the first year of life. The number of total days of coughing was correlated to the use of wood-burning stoves $(\mathrm{OR}=1.10$; IC 95\% 1.02-1.19), while the number of episodes of coughing was related to the use of kerosene heaters (1.07; IC 95\% 1.00-1.15). The number of total days of wheezing, on the other hand, was associated with the use of gas heaters ( 1.25 ; IC 95\% 1.05-1.50).

Studies Conducted in Europe. In a cohort study, in this case carried out retrospectively, conducted in Finland (2001), the authors identified living on a farm between the ages of 0 to 6 years as a protective factor against allergic rhinoconjunctivitis with an OR of $0.51(0.5-0.75, P<.0001)$. In this sample population, living on a farm was frequent for subjects whose houses were heated with wood stoves [23].

In Teplice (Czech Republic), a cohort of 452 children was followed up to the age of 3 . The authors analyzed the correlation between exposure to various types of domestic pollutants with the incidence of LRTIs (excluding pneumonia). After adjusting for different covariables, the authors 


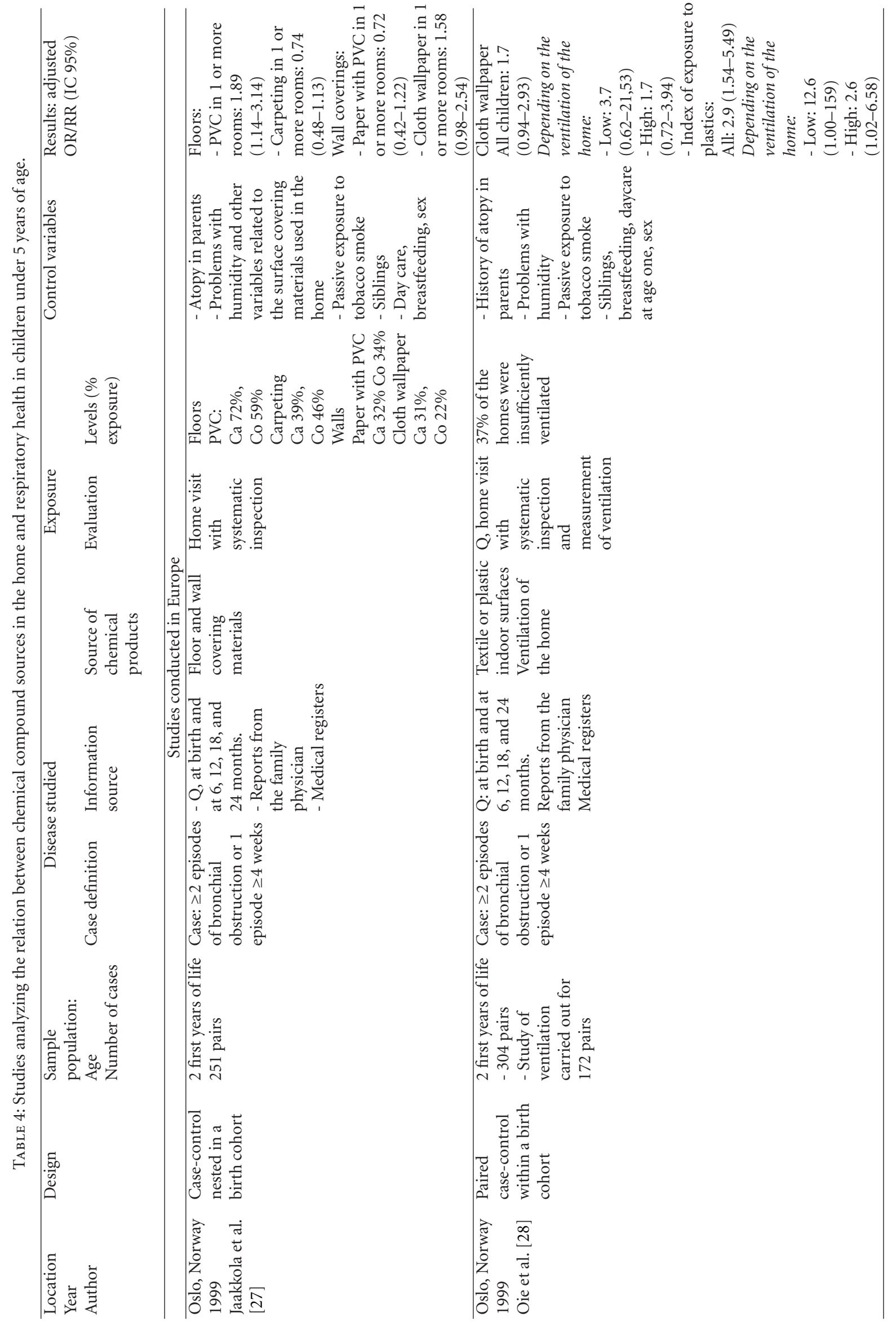




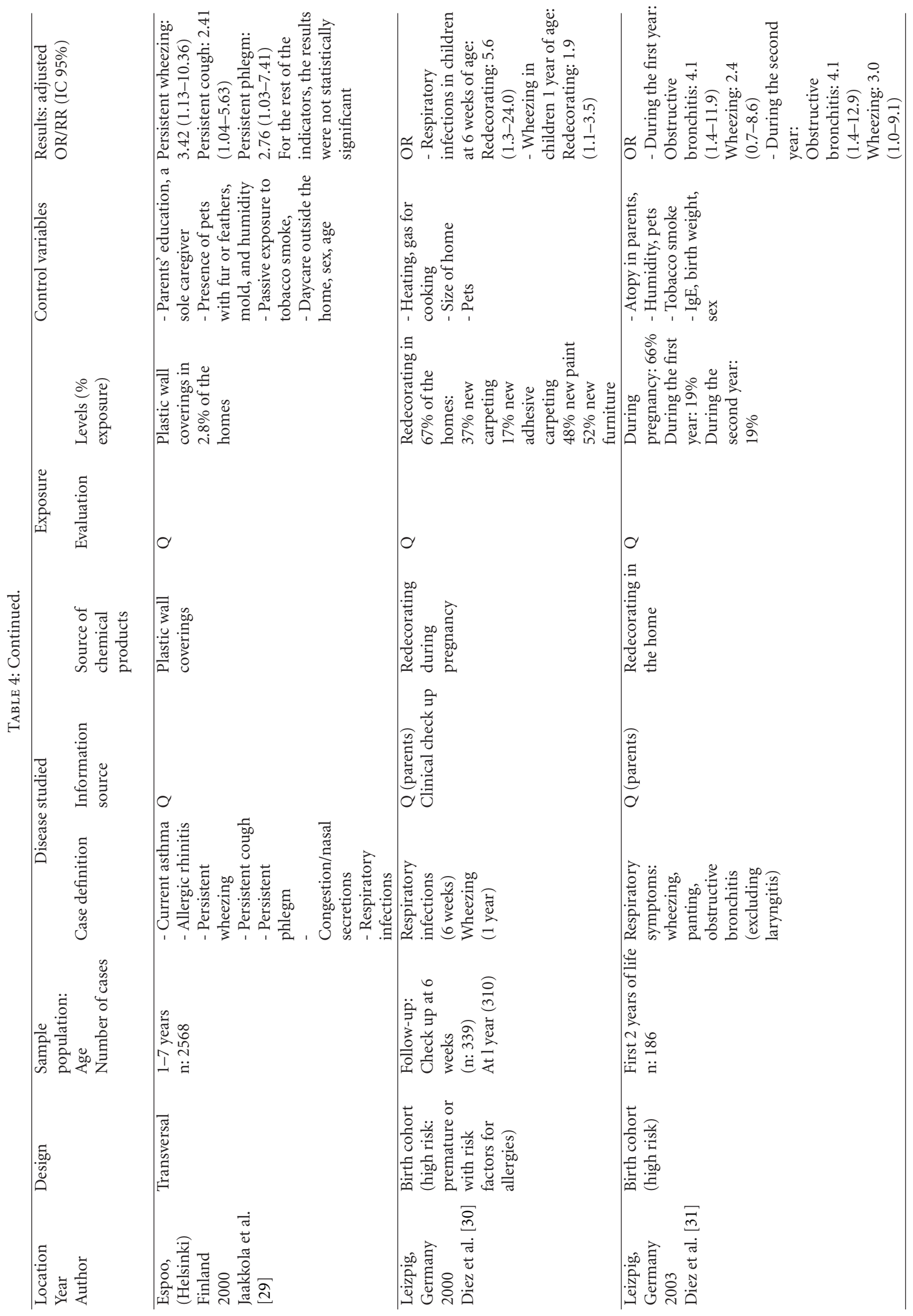




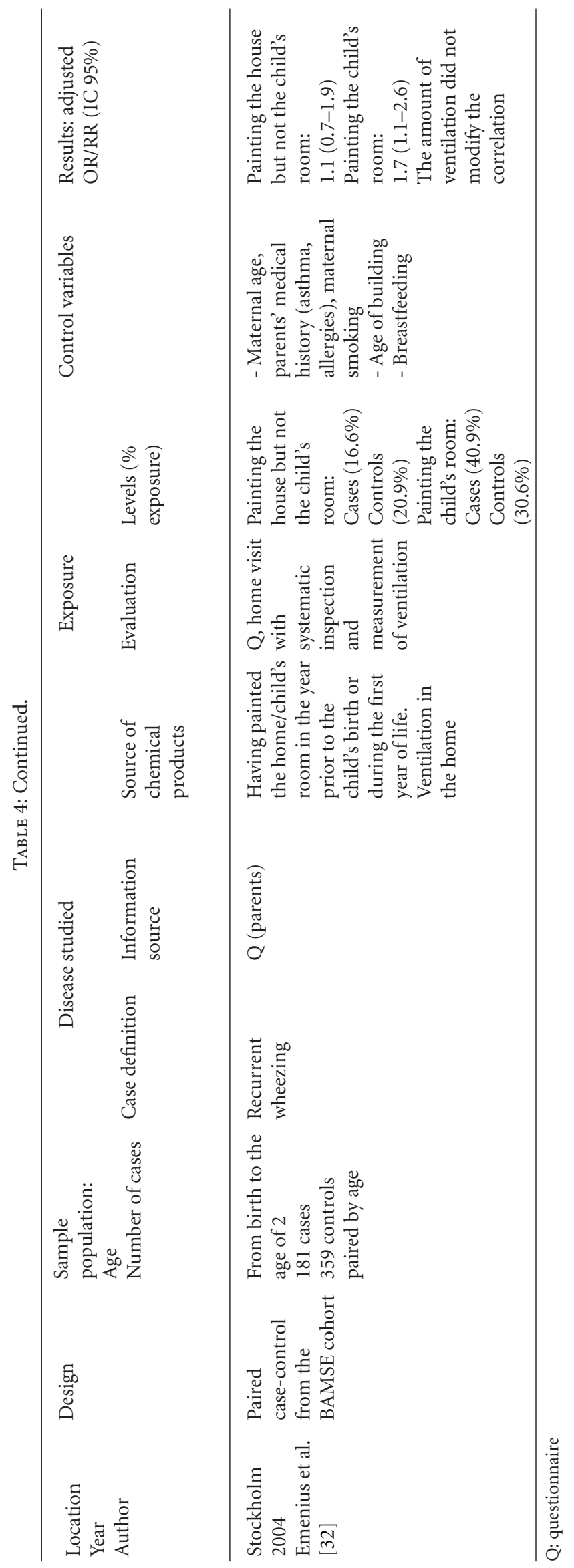


found a significant increase in the incidence of LRTIs in those children living in coal-heated. This correlation was higher still if the child had not been breastfed (RR 2.77; IC 95\% 1.45-5.27). Other energy sources such as natural gas or propane were not significantly linked to the incidence of LRTIs [24].

3.1.3. Studies Analyzing the Relationship between Sources of Indoor Pollution from Chemical Products and Respiratory Problems (Table 4). Six of the studies analyzed the relationship between sources of chemical compounds in the home and the respiratory health of young children. All of these studies were conducted in Northern European countries and all but one were conducted within the framework of various birth cohorts.

In the Oslo (Norway) birth cohort, various nested casecontrol studies were carried out. In the first one, Jaakkola et al. [27] examined 251 case-control pairings to determine the relationship between bronchial obstruction during the first years of life and the presence of polyvinyl chloride (PVC) in the plastics, carpeting, and other wall and floor coverings in one or more rooms of the home. The authors found significant correlations between bronchial obstruction and the use of PVC as a flooring material or floor covering (OR: 1.89; IC 95\%: 1.14-3.14) as opposed to wood or parquet. They also found a relation that was just below significance between this particular respiratory symptom and the use of wallpaper (OR: 1.58; IC 95\%: 0.98-2.54) as compared to painted walls.

Another study of the same cohort [28] used a larger sample (304 case-control pairs) to analyze the impact of using either paper or plastic wallpaper. The novelty of this study was that the possibly modifying role of ventilation was evaluated, although for this particular factor, measurements were carried out for only 172 pairs. The results for the entire sample confirmed those of the afore-mentioned study [27]. The authors also found that the impact was greater on children who lived in homes with poor ventilation $37 \%$ of all the homes in the sample).

One of the researchers from the previous studies, Jaakkola et al., also conducted a study on the effect of plastic wall and floor coverings on the child population of Finland [29]. Within the framework of a populational transversal design, the author analyzed the relationship between exposure to said materials and the incidence of illnesses (such as asthma) and symptoms, including wheezing or persistent cough, in 2568 children between the ages of 1 and 7 . The results showed that the emissions of these materials within the home could have adverse effects on the respiratory health of children, with significant correlations between the presence of these materials and persistent wheezing, cough, and phlegm.

Diez et al. conducted two studies on the correlation between redecorating activities and respiratory effects in children with allergy risk factors in the Leipzig (Germany) cohort LARS [30, 31]. The first study [30] evaluated the influence of the exposure to products used for redecorating the home during pregnancy on respiratory problems in the child's first year of life. In the majority of cases, children of parents who had undertaken activities such as painting or changing the carpeting presented a higher risk of suffering pulmonary infections during the first 6 weeks of life (OR: 5.60; IC 95\% 1.30-24.00) and also of having episodes of wheezing during the first year (OR: 1.90; IC 95\% 1.103.50). The authors also measured the indoor levels of several volatile organic compounds and found the highest styrene levels in homes in which new wall-to-wall carpeting had been installed. Furthermore, upon studying the relationship between these compounds and health problems, they observed a correlation between respiratory infections at 6 weeks and living in houses with styrene levels $>2.0 \mu \mathrm{g} / \mathrm{m}^{3}$ and benzene levels $>5.6 \mu \mathrm{g} / \mathrm{m}^{3}$ (OR: $2.10(1.10-4.20)$ and 2.40 (1.30-4.50), resp.). Nevertheless, the authors did not provide any results concerning the possible correlation between volatile organic compounds and wheezing in the first year of life.

In their second study using the LARS cohort, Diez et al. [31] followed a subset of 186 of the aforementioned children up to the age of two, collecting information about decorating activity in the home and respiratory symptoms. The results indicate that decorating activities have an important influence on the appearance of obstructive bronchitis during the first and second years of life, with statistically significant ORs greater than 4 . The effect of such activity on the incidence of wheezing was lower, but also significant (OR: 3.00; IC 95\% 1.00-9.10).

Finally, Emenius et al. [32] also studied the correlation between having painted an area within the house (or, specifically, the child's room), ventilation, and the incidence of recurrent wheezing up until the second year of life. The authors found a relationship between having recently painted the child's room and recurrent wheezing (OR: 1.70; IC 95\% 1.30-2.60). This correlation did not change when adjusted for the amount of ventilation in the home.

3.2. Discussion. In the studies analyzing the correlation between the use of gas energy sources and respiratory health in young children, the results vary for the most part depending on the geographic/cultural context in which the studies were carried out. In most of the studies conducted in developed countries, gas energy sources were associated with an increase in various indicators of respiratory health, especially symptoms of bronchial obstruction/asthma (coughing, wheezing), but not necessarily respiratory infections. In these studies the energy source used as a reference was one that was supposed to pollute less, such as electricity. However, in the developing countries gas energy sources formed part of the reference category against which the impacts of more highly pollutant energy sources such as wood, coal, or animal waste were compared. In this context, one can safely say that the substitution of these types of fuel with a gas energy source would lead to improvements in the indicators analyzed.

Solid fuels constitute the principal source of energy in the homes of nearly 3 billion people. Their use is clearly linked to poverty, a condition that implies poor access to a healthcare system. The results of the studies carried out 
to date along with various other evaluations of the impact of air pollution from the use of biomass on health in the world indicate that indoor pollution in the poorer countries is one of the principal causes of death in the world $[34,35]$. For this reason, the evaluation and application of effective intervention strategies should form a part of the policy priorities for public health at the global level [36, 37]. Use of this type of fuel has also been documented in the Scandinavian countries, mostly due to the use of woodburning stoves for heating. However, factors such as living near a farm, most likely along with other variables, act as confounders, leading to the idea that this type of fuel can act as a protective factor against allergy problems such as asthma $[23,38]$.

Recently, various studies conducted in northern Europe have shown that there is a group of sources of chemical compounds found in the home that are related to increased risk of respiratory diseases [27-31]. The authors of both the Norwegian cohort study $[27,28]$ and the Finnish transversal [29] study found a relationship between respiratory problems in children when PVC or other plastics were used as wall coverings in the home. One group of chemical compounds used in the manufacture of plastics is that of the phthalates. These compounds can be released into the indoor atmosphere of the home and become incorporated into the organism of the people thus exposed [36]. Indeed, various recent studies have evaluated the relationship between these compounds and allergic and respiratory problems in children.

Bornehag et al. [39] studied the possible correlations between the concentration of various phthalates in house dust and allergic symptoms in a study using 200 casecontrol pairs nested in a cohort of children in Sweden. The results indicate that there is an association between certain phthalates and rhinitis, eczema, and asthma, even when the phthalate levels fall within the normal range for these compounds in Sweden. Kolarik et al. [40] analyzed the same relationship in 102 children between the ages of 2 and 7 who had exhibited allergic symptoms in the past 12 months and 80 controls living in Sofia and Burgas (Bulgaria). The results indicated a significant correlation between several of the phthalates analyzed and the incidence of wheezing.

In the other three studies included in this review, the exposure factor studied was the case in which decorating and/or construction work had been carried out at home, especially the recent painting of the child's room or the installation of wall-to-wall carpeting [30, 31, 41]. In a recent review [39], Mendell found that aliphatic compounds were correlated to painting in the home and, what is more, that these compounds were associated with immunological changes. In addition, certain types of wall-to-wall carpeting used in Germany have been found to be related to the emission of volatile organic compounds.

\section{Conclusions}

The distribution by country of the studies examining various pollution sources reveals a clear relationship between lifestyle habits and the degree of development. For example, most of the studies on gas $\left(\mathrm{NO}_{2}\right)$ sources were conducted in Western countries, with only two being carried out in the developing world. In contrast, studies concerned with biomass fuels were mostly carried out in developing nations. With respect to indoor pollution due to sources that emit chemical compounds, the only studies found were conducted in Northern Europe.

The correlation between wood fuel and respiratory problems is clearly documented in the developing world. For example, according to a recent, exhaustive study carried out by the World Health Organization [38], the risk of young children (under 5 years of age) contracting pneumonia has been observed to increase by $80 \%$ when they are exposed to the combustion of solid, unprocessed fuels.

The principal pollutant of gas energy sources is $\mathrm{NO}_{2}$. In those studies in which the role of this compound was also included, the general tendency was that its effect was similar, both in direction and magnitude, to that assigned to gas energy sources in general. Taking this into account, we can hypothesize that the effect observed for the gas energy sources is probably mediated by the action of $\mathrm{NO}_{2}$. This remains uncertain, however, since none of the studies introduced both the indicator of the energy source and the $\mathrm{NO}_{2}$ levels in the same multivariate model.

All of the studies about chemical compounds found in home and respiratory health of children have in common the fact that they were carried out in cold areas in which there is less ventilation of the home and where the uses of wallto-wall carpeting and insulation are frequent. All the studies observed significant correlations between the presence of these materials in the home and respiratory problems in children.

The European Union has yet to establish guidelines for indoor pollutants, probably due to the absence of a systematic study of the risks that these contaminants pose for human health. According to the results of the THADE ("Towards Healthy Air in Dwellings in Europe") study published in 2006, there is a lack of evidence-based information on the appropriate measures for preventing adverse effects on health caused by indoor pollution [42]. Also, for most of the pollutants, their effects on human health are highly debatable [43]. It would thus be beneficial to conduct studies determining these risks for the most vulnerable members of the population, including, for example, children.

In this review it was not possible to summarize the results of the studies through metanalysis due to the lack of a minimum number of studies with the same design, analyzing the same exposure source on the same result indicator within comparable populations. Likewise, we cannot rule out a certain bias in the publications chosen, which could obviate the results of other studies that we were unable to identify with our search strategies and criteria. Nevertheless, it is worth noting that the strategy used was exhaustive in nature and included the revision of references included in the bibliographies of the studies thus selected.

The use of pollution sources as an exposure variable could be a disadvantage with respect to the study of the impact of the concentrations of individual pollutants, especially when establishing norms and regulations for 
appropriate levels of these substances. There are, however, advantages to this strategy in that it allows for the analysis of a given exposure as a complex mixture of pollutants which, if studied individually, could lead to confusion bias due to correlations between the various components. Furthermore, it is much simpler to monitor and translate the results of such studies into preventative measures to be divulged either to the general population or to certain risk groups in order to decrease their exposure to pollution within their own homes.

\section{References}

[1] F. V. Marcos and I. G. Pulgarín, "Calidad ambiental interior: bienestar, confort y salud," Revista Española de Salud Publica, vol. 79, no. 2, pp. 243-251, 2005.

[2] J. Schwartz, "Air pollution and children's health," Pediatrics, vol. 113, no. 4, supplement, pp. 1037-1043, 2004.

[3] J. Zhang and K. R. Smith, "Indoor air pollution: a global health concern," British Medical Bulletin, vol. 68, pp. 209-225, 2003.

[4] World Health Organization, "Indoor air pollution and health," WHO-Fact sheet 2005292, http://www.who.int/mediacentre/ factsheets/fs292/en/.

[5] World Health Organization, "Indoor air pollution: national burden of disease estimates," Tech. Rep. WHO/SDE/PHE/07 .01rev, World Health Organization, Geneva, Switzerland, 2007.

[6] World Health Organization, "World health report 2005: make every mother and child count," Tech. Rep., World Health Organization, Geneva, Switzerland, 2005.

[7] V. Fuentes-Leonarte, J. M. Tenías, and F. Ballester, "Levels of pollutants in indoor air and respiratory health in preschool children: a systematic review," Pediatric Pulmonology, vol. 44, no. 3, pp. 231-243, 2009.

[8] M. B. Aldous, C. J. Holberg, A. L. Wright, F. D. Martinez, and L. M. Taussig, "Evaporative cooling and other home factors and lower respiratory tract illness during the first year of life. Group Health Medical Associates," American Journal of Epidemiology, vol. 143, no. 5, pp. 423-430, 1996.

[9] E. W. Triche, K. Belanger, W. Beckett, et al., "Infant respiratory symptoms associated with indoor heating sources," American Journal of Respiratory and Critical Care Medicine, vol. 166, no. 8, pp. 1105-1111, 2002.

[10] K. Belanger, W. Beckett, E. Triche, et al., "Symptoms of wheeze and persistent cough in the first year of life: associations with indoor allergens, air contaminants, and maternal history of asthma," American Journal of Epidemiology, vol. 158, no. 3, pp. 195-202, 2003.

[11] K. Belanger, J. F. Gent, E. W. Triche, M. B. Bracken, and B. P. Leaderer, "Association of indoor nitrogen dioxide exposure with respiratory symptoms in children with asthma," American Journal of Respiratory and Critical Care Medicine, vol. 173, no. 3, pp. 297-303, 2006.

[12] G. Emenius, G. Pershagen, N. Berglind, et al., " $\mathrm{NO}_{2}$, as a marker of air pollution, and recurrent wheezing in children: a nested case-control study within the BAMSE birth cohort," Occupational and Environmental Medicine, vol. 60, no. 11, pp. 876-881, 2003.

[13] J. Sunyer, C. Puig, M. Torrent, et al., "Nitrogen dioxide is not associated with respiratory infection during the first year of life," International Journal of Epidemiology, vol. 33, no. 1, pp. 116-120, 2004.
[14] V. Mishra, "Indoor air pollution from biomass combustion and acute respiratory illness in preschool age children in Zimbabwe," International Journal of Epidemiology, vol. 32, no. 5, pp. 847-853, 2003.

[15] D. Singh, V. Arora, and P. C. Sobti, "Chronic/recurrent cough in rural children in Ludhiana, Punjab," Indian Pediatrics, vol. 39, no. 1, pp. 23-29, 2002.

[16] I. A. Kristensen and J. Olsen, "Determinants of acute respiratory infections in Soweto-a population-based birth cohort," South African Medical Journal, vol. 96, no. 7, pp. 633-640, 2006.

[17] S. Sharma, G. Rai Sethi, A. Rohtagi, et al., "Indoor air quality and acute lower respiratory infection in Indian urban slums," Environmental Health Perspectives, vol. 106, no. 5, pp. 291-297, 1998.

[18] S. Broor, R. M. Pandey, M. Ghosh, et al., "Risk factors for severe acute lower respiratory tract infection in under-five children," Indian Pediatrics, vol. 38, no. 12, pp. 1361-1369, 2001.

[19] D. Mahalanabis, S. Gupta, D. Paul, A. Gupta, M. Lahiri, and M. A. Khaled, "Risk factors for pneumonia in infants and young children and the role of solid fuel for cooking: a case-control study," Epidemiology and Infection, vol. 129, no. 1, pp. 65-71, 2002.

[20] M. Khalequzzaman, M. Kamijima, K. Sakai, N. A. Chowdhury, N. Hamajima, and T. Nakajima, "Indoor air pollution and its impact on children under five years old in Bangladesh," Indoor Air, vol. 17, no. 4, pp. 297-304, 2007.

[21] M. A. Schei, J. O. Hessen, K. R. Smith, N. Bruce, J. McCracken, and V. Lopez, "Childhood asthma and indoor woodsmoke from cooking in Guatemala," Journal of Exposure Analysis and Environmental Epidemiology, vol. 14, supplement 1, pp. S110S117, 2004.

[22] L. F. Robin, P. S. J. Lees, M. Winget, et al., "Wood-burning stoves and lower respiratory illnesses in Navajo children," Pediatric Infectious Disease Journal, vol. 15, no. 10, pp. 859865, 1996.

[23] M. Kilpelainen, M. Koskenvuo, H. Helenius, and E. Terho, "Wood stove heating, asthma and allergies," Respiratory Medicine, vol. 95, no. 11, pp. 911-916, 2001.

[24] R. J. Baker, I. Hertz-Picciotto, M. Dostál, et al., "Coal home heating and environmental tobacco smoke in relation to lower respiratory illness in Czech children, from birth to 3 years of age," Environmental Health Perspectives, vol. 114, no. 7, pp. 1126-1132, 2006.

[25] Ó. García Algar, S. Pichini, X. Basagaña, et al., "Concentrations and determinants of $\mathrm{NO}_{2}$ in homes of Ashford, UK and Barcelona and Menorca, Spain," Indoor Air, vol. 14, no. 4, pp. 298-304, 2004.

[26] V. Mishra and R. D. Retherford, "Does biofuel smoke contribute to anaemia and stunting in early childhood?" International Journal of Epidemiology, vol. 36, no. 1, pp. 117129, 2007.

[27] J. J. K. Jaakkola, L. Øie, P. Nafstad, G. Botten, S. O. Samuelsen, and P. Magnus, "Interior surface materials in the home and the development of bronchial obstruction in young children in Oslo, Norway," American Journal of Public Health, vol. 89, no. 2, pp. 188-192, 1999.

[28] L. $\varnothing$ ie, P. Nafstad, C. Botten, P. Magnus, and J. J. K. Jaakkola, "Ventilation in homes and bronchial obstruction in young children," Epidemiology, vol. 10, no. 3, pp. 294-299, 1999. 
[29] J. J. K. Jaakkola, P. K. Verkasalo, and N. Jaakkola, "Plastic wall materials in the home and respiratory health in young children," American Journal of Public Health, vol. 90, no. 5, pp. 797-799, 2000.

[30] U. Diez, T. Kroeßner, M. Rehwagen, et al., "Effects of indoor painting and smoking on airway symptoms in atopy risk children in the first year of life results of the LARS-study," International Journal of Hygiene and Environmental Health, vol. 203, no. 1, pp. 23-28, 2000.

[31] U. Diez, M. Rehwagen, U. Rolle-Kampczyk, et al., "Redecoration of apartments promotes obstructive bronchitis in atopy risk infants-results of the LARS study," International Journal of Hygiene and Environmental Health, vol. 206, no. 3, pp. 173$179,2003$.

[32] G. Emenius, M. Svartengren, J. Korsgaard, L. Nordvall, G. Pershagen, and M. Wickman, "Indoor exposures and recurrent wheezing in infants: a study in the BAMSE cohort," Acta Paediatrica, International Journal of Paediatrics, vol. 93, no. 7, pp. 899-905, 2004.

[33] H. Riojas-Rodríguez, P. Romano-Riquer, C. Santos-Burgoa, and K. R. Smith, "Household firewood use and the health of children and women of indian communities in Chiapas, Mexico," International Journal of Occupational and Environmental Health, vol. 7, no. 1, pp. 44-53, 2001.

[34] M. Ezzati, A. D. Lopez, A. Rodgers, S. Vander Hoorn, and C. J. L. Murray, "Selected major risk factors and global and regional burden of disease," The Lancet, vol. 360, no. 9343, pp. 13471360, 2002.

[35] M. Dherani, D. Pope, M. Mascarenhas, K. R. Smith, M. Weber, and N. Bruce, "Indoor air pollution from unprocessed solid fuel use and pneumonia risk in children aged under five years: a systematic review and meta-analysis," Bulletin of the World Health Organization, vol. 86, no. 5, pp. 390-398, 2008.

[36] M. Ezzati, J. Utzinger, S. Cairncross, A. J. Cohen, and B. H. Singer, "Environmental risks in the developing world: exposure indicators for evaluating interventions, programmes, and policies," Journal of Epidemiology and Community Health, vol. 59, no. 1, pp. 15-22, 2005.

[37] D. G. Fullerton and S. Semple, "Air pollution and health: indoor air pollution in the developing world is the real key to reducing the burden of ill health," Thorax, vol. 63, no. 3, p. $288,2008$.

[38] H. Duhme, S. K. Weiland, P. Rudolph, A. Wienke, A. Kramer, and U. Keil, "Asthma and allergies among children in west and east Germany: a comparison between Münster and Greifswald using the ISAAC phase I protocol. International Study of Asthma and Allergies in Childhood," European Respiratory Journal, vol. 11, no. 4, pp. 840-847, 1998.

[39] C.-G. Bornehag, J. Sundell, C. J. Weschler, et al., "The association between asthma and allergic symptoms in children and phthalates in house dust: a nested case-control study," Environmental Health Perspectives, vol. 112, no. 14, pp. 13931397, 2004.

[40] B. Kolarik, K. Naydenov, M. Larsson, C. G. Bornehag, and J. Sundell, "The association between phthalates in dust and allergic diseases among Bulgarian children," Environmental health perspectives, vol. 116, no. 1, pp. 98-103, 2008.

[41] G. Emenius, M. Svartengren, J. Korsgaard, L. Nordvall, G. Pershagen, and M. Wickman, "Indoor exposures and recurrent wheezing in infants: a study in the BAMSE cohort," Acta Paediatrica, vol. 93, no. 7, pp. 899-905, 2004.

[42] M. Franchi, P. Carrer, D. Kotzias, et al., "Working towards healthy air in dwellings in Europe," Allergy, vol. 61, no. 7, pp. 864-868, 2006.
[43] K. Koistinen, D. Kotzias, S. Kephalopoulos, et al., “The INDEX project: executive summary of a European Union project on indoor air pollutants," Allergy, vol. 63, no. 7, pp. 810-9, 2008. 


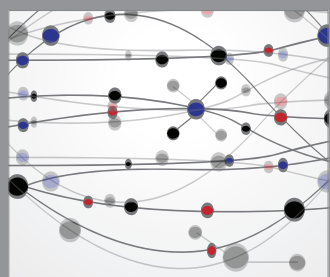

The Scientific World Journal
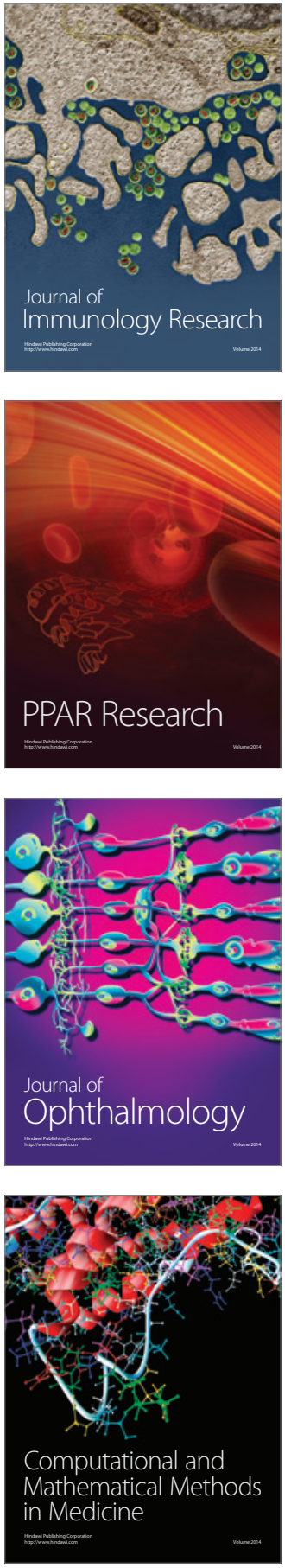

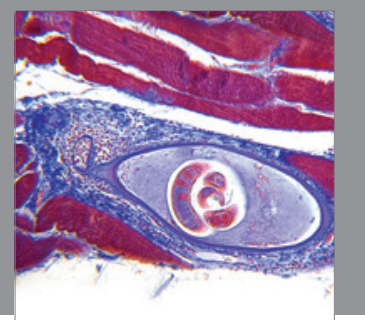

Gastroenterology

Research and Practice
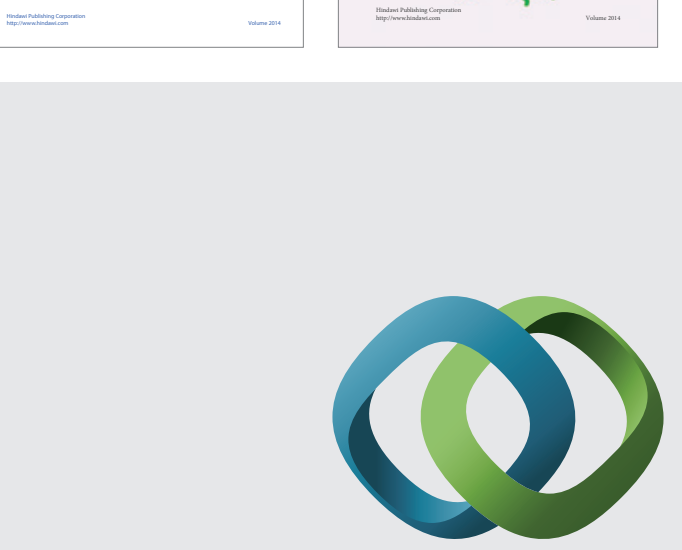

\section{Hindawi}

Submit your manuscripts at

http://www.hindawi.com
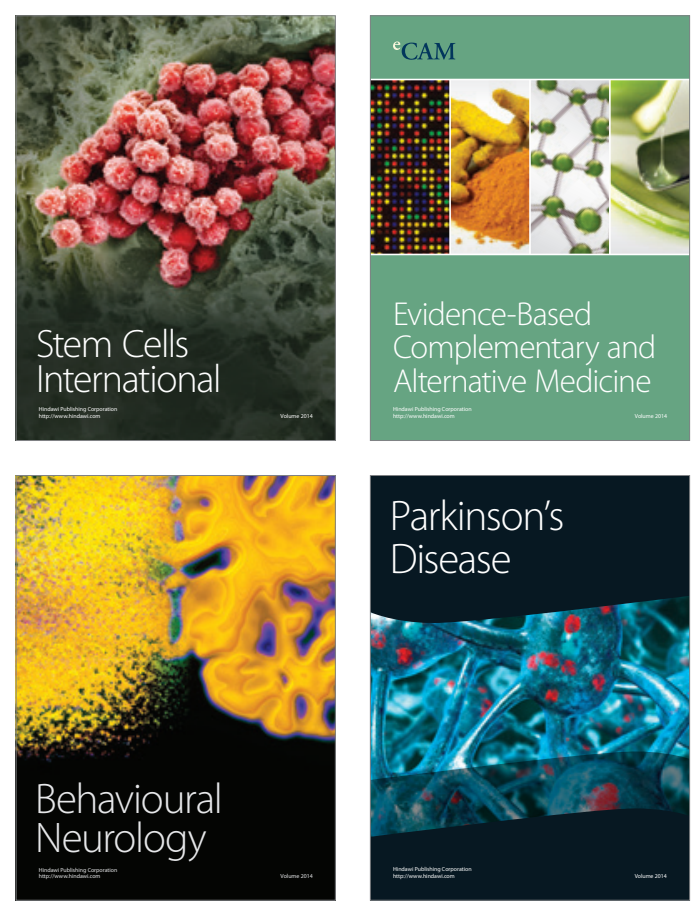

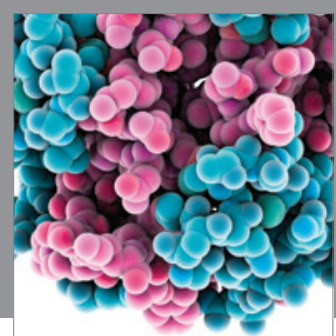

Journal of
Diabetes Research

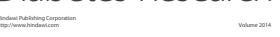

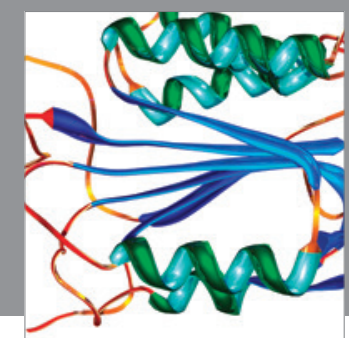

Disease Markers
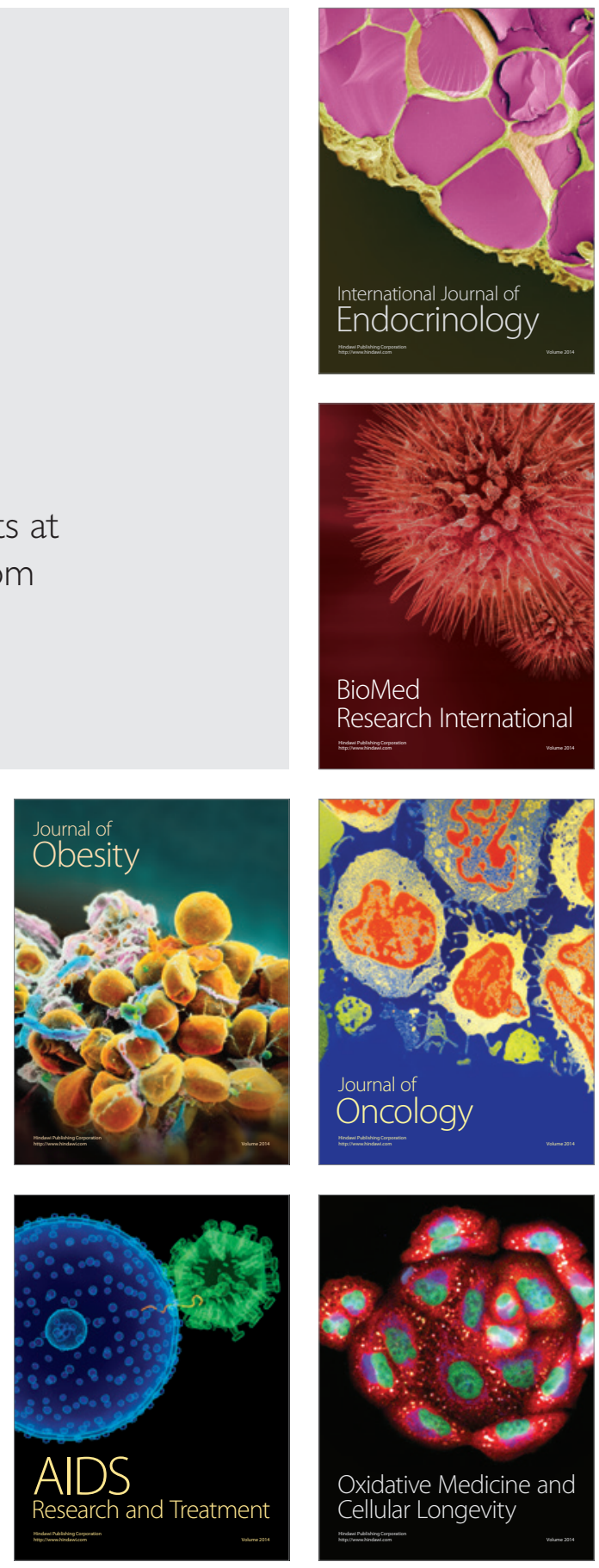